\title{
Improving Community Sanitation and Hygiene Performance in Kerwa Sub County through the Application of Statistical Thinking
}

\author{
Article by Omona Kizito \\ Ph.D. in Healthcare Administration, Texila American University \\ E-mail: kizitoomona@gmail.com
}

\begin{abstract}
Introduction: Sanitation refers to the provision of facilities and services for the safe disposal of human urine and faeces whereas Hygiene is a set of personal practices that contribute to good health. It includes things like hand-washing, bathing and so forth.

Objectives: The purpose and rationale of this project was to improve sanitation and hygiene in Kerwa Sub county.

Methods: The project (2years) employed both qualitative and quantitative mixed designs in Kerwa Sub county, located, in Yumbe district, Uganda. Implementation period was from April, 2015 to November, 2016.

Results: The total number of households with latrines increased from 775 (43.3\%) in the baseline to $1215(67.8 \%)$ in the first year of project implementation then to 1579 (88.2\%) in the second year. Similarly, open defecation dropped from $56.7 \%$ in the baseline to $32.2 \%$ in the first year of project implementation and further to $11.8 \%$ in the second year. Hygiene status, measured using hand washing, almost remained the same between baseline and first year of project implementation at about $0.9 \%$. It significantly improved to $20.8 \%$ in the second year. Through application of statistical thinking, final reporting time reduced by 60 days, from 210 days before statistical thinking approach to 150 days after the application.

Conclusion: Statistical thinking remains a key process of continuous quality improvement in any industry.
\end{abstract}

Keywords: Sanitation and hygiene, statistical thinking.

\section{Introduction}

This cover general introduction to the topic, problem statement and objectives of the project.

\section{Introduction to the topic}

Sanitation refers to the provision of facilities and services for the safe disposal of human urine and faeces. Inadequate sanitation is a major cause of disease world-wide and improving sanitation is known to have a significant beneficial impact on health both in households and across communities (World Health Organization [WHO], 2017). On the other hand, Dig Deep (2017) defined Sanitation as the effective use of tools and actions that keep our environment healthy. These include latrines or toilets to manage waste, food preparation, washing stations, effective drainage and other such mechanisms. Similarly, Hygiene is a set of personal practices that contribute to good health. It includes things like hand-washing, bathing and cutting hair/nails. Hand-washing is the single most important activity we can all do to encourage the stop of disease (Dig Deep, 2017).

Statistical thinking is a philosophy of learning and action based on the following three fundamental principles; All work occurs in a system of interconnected processes, Variation exists in all processes and understanding and reducing variation are keys to successes (Galen, et al., 2010; Doug, et al., 2000). Successful organizations learn and grow. Learning requires accumulation of information, usually by taking the right amount of the right kind of data to make decisions for improvement. Learning without action is wasteful and useless (Galen et al., 2010). In fact, Amazon (2017) argued that the world continues to become increasingly complex and competitive, with change being driven by increasing customer demands for better products and more responsive services. They further added that because of this competition, improvement is critical to survival and progress; often the rate of improvement determines the winners and losers. For those organizations striving to make improvement, "Improving Performance through Statistical Thinking" presents a clear and practical explanation. 
Lack of access to safe, clean drinking-water and basic sanitation, as well as poor hygiene cause nearly $90 \%$ of all deaths from diarrhoea, mainly in children. Whereas $87 \%$ of the world's population have access to improved water sources, $39 \%$ still lack access to improved sanitation. Even then in developing countries about 1.1 billion people still defecate in the open and hand washing with soap is practiced, on average, only after $17 \%$ of toilet uses (WHO, 2011).

\section{Statement of the problem}

The major problem was poor sanitation and hygiene in Kerwa Sub county, marked with rampant open defecation. The effect of this was the high sanitation and hygiene disease burden in the sub-county. This increased expenditure on healthcare in the nearby health centre, that is Midigo Health Centre IV, to which Calvary chapel of Midigo (faith base organization) was a major financial contributor.

Calvary Chapel Midigo embarked on a campaign to improve the community sanitation and hygiene in Kerwa sub-county. The organization got troubled with the delayed documentary progressive reporting by field staffs. It was discovered that it took 210 days to implement activities and document monthly progress reports for the sub county against management expectation of 180 days. The shorter time frame would improve the organization financial flow from donor but also help customers to complete their sanitation and hygiene tasks in time.

\section{Project objectives}

The project had two objectives/purposes;

I. To improve sanitation and hygiene in Kerwa Sub county within fixed time frame in keeping with Result Based Financing (RBF) from donors between April, 2015 and November, 2016.

II. To reduce final reporting time from 210 days to 180 days through the application of statistical thinking approach, between April, 2016 to November, 2016.

\section{Methodology used}

\section{Introduction}

This chapter outlines the methodology to used. It includes the study design and setting and their rationale, the project duration, setting, study population, project dilemma and how they were used to solve the problems. Data collection, management and analysis, ethical considerations, definition of variables, limitation and dissemination of the report, are as well outlined.

\section{The study design and its rationale}

The project employed both qualitative and quantitative mixed designs. The mixed design gave all the detailed information that were needed for the project. The rationale of project was to improve sanitation and hygiene in Kerwa Sub county within fixed time frame in keeping with Result Based Financing (RBF) from donors.

\section{Project duration}

The project lasted for a period of two years April, 2015 - November, 2016. It had two project cycles. Each cycle lasted for 6 months (180 days) per year. When the first cycle ended, the next cycle would then start in April of the following year. Possible extension was subject to financial availability from donor as well as results achieved.

\section{The study setting (area)}

The project was implemented in Kerwa Sub county, located, in Yumbe district (West Nile region), Uganda. The sub county is bordered by South Sudan in the North, Midigo Sub county in the South, Kei Sub County in the West and Moyo district in the East. Both Midigo Sub county and Kei Sub counties are sub counties within Yumbe district and all, including Kerwa itself, are located in Aringa North Health Sub District. Moyo district is another district in Uganda that is located within West Nile region and it is bordering Yumbe district.

The sub county (kerwa), has a total population of 29,000people. This number keeps varying due to frequent cross border migration between Ugandan and South Sudanese who share common ancestry. The indigenous population are predominantly Kakwa. The major occupation of the community is subsistent farming (UBOS, 2014). 
The survey was conducted in 43villages ( 6 parishes) in Kerwa sub county. These were; Kerwa Parish (6 villages), Kopionga Parish (9 villages), Wandi Parish (8 villages), Mijikita Parish (6 villages), Rodo Parish (8 villages) and Usubira Parish (6 villages). The whole exercise took 60 working days as opposed to the estimated 43 working days in the work plan.

\section{Study population and units}

This formed the total number of people who were eligible to be sampled to participate in the study. The study population was, therefore, the entire community of Kerwa with a total of about 1791 households. The study units were the individual households

\section{Sample size estimation}

Since the project rationale was to improve sanitation and hygiene in the whole sub county, the entire 1791 House Holds (HH) were included in the study.

Hence;

Sample size $=\mathbf{1 7 9 1 H o u s e ~ H o l d s ~}$

\section{Project dilemma}

The problem in this project was poor sanitation and hygiene in Kerwa Sub county. Calvary chapel of Midigo embarked on a campaign to improve the community sanitation and hygiene in Kerwa. The organization got troubled with the delayed documentary progress reporting by the field staffs in the first year of implementation. The organization discovered that it took 210days to implement activities and document final report for the sub county against management expectation of 180 days. The shorter time frame would improve the organization financial flow from donor but also help customers to complete their sanitation and hygiene tasks in time. Monthly progress reports were mandatory deliverables of the project.

\section{Digesting the problem/dilemma}

Assessing the project implementation process revealed that three different sub groups of field staffs were involved in completing and documenting reports. The field staffs were grouped as; Group A, Group B and Group C. Each group worked separately and were expected to produce evidence based results in a well thought out single report for the three groups. None of the groups understood the implementation process from end to end. When problems occurred in first year, there was a lot of finger pointing, hence delayed reporting. Similarly, there was no standard operating procedures, that is formal, agreed upon of getting the job done. Every group performed their jobs differently and this resulted in considerable firefighting to complete the reports within required time frame.

However, one clear cut advantage was that a quantitative measure existed to monitor the performance of the implementation process - the number of days required to implement and produce reports.

\section{Solving the problem through application of statistical thinking}

A project team was organized to ensure that the whole system was improved and to obtain various viewpoints on the problem. The team created a system map for the overall process, along with flow chart of critical process steps. The system map identified the responsible groups and what flowed back and forth among them. The flow chart became the foundation of a new production schedule for the monthly progress reporting and the final report. This schedule aligned the organization, Calvary Chapel Midigo, with what had to be done each month by which group and by when.

Next, the team identified critical sub-processes (Community led total Sanitation meetings) at village levels and monitored time measurement for each of them as well as for the overall process. These measurements enabled identification of key problem areas. Again, cross-functional sub-teams provided daily troubleshooting and review of daily performance. Problems and procedures for creating and implementing solutions were identified.

Next, the team initiated efforts to document the process. This helped a lot to reduce procedural variations among the three field staff groups A, B and C. They started doing things similarly, and this formed the basis for training new employees. A project coordinator was assigned. His job was to take care of the health of the process by seeing into it that the process management was used and improved to handle the changing conditions the implementation process would experience. 
DOI: $10.21522 /$ TIJPH.2013.06.01.Art005

ISSN: $2520-3134$

The use of statistical thinking approach significantly improved the operation of the implementation process of the project. Over the remaining one years' period, the progressive monthly reporting became timely and final reporting days reduced from 210 days to 150 days.

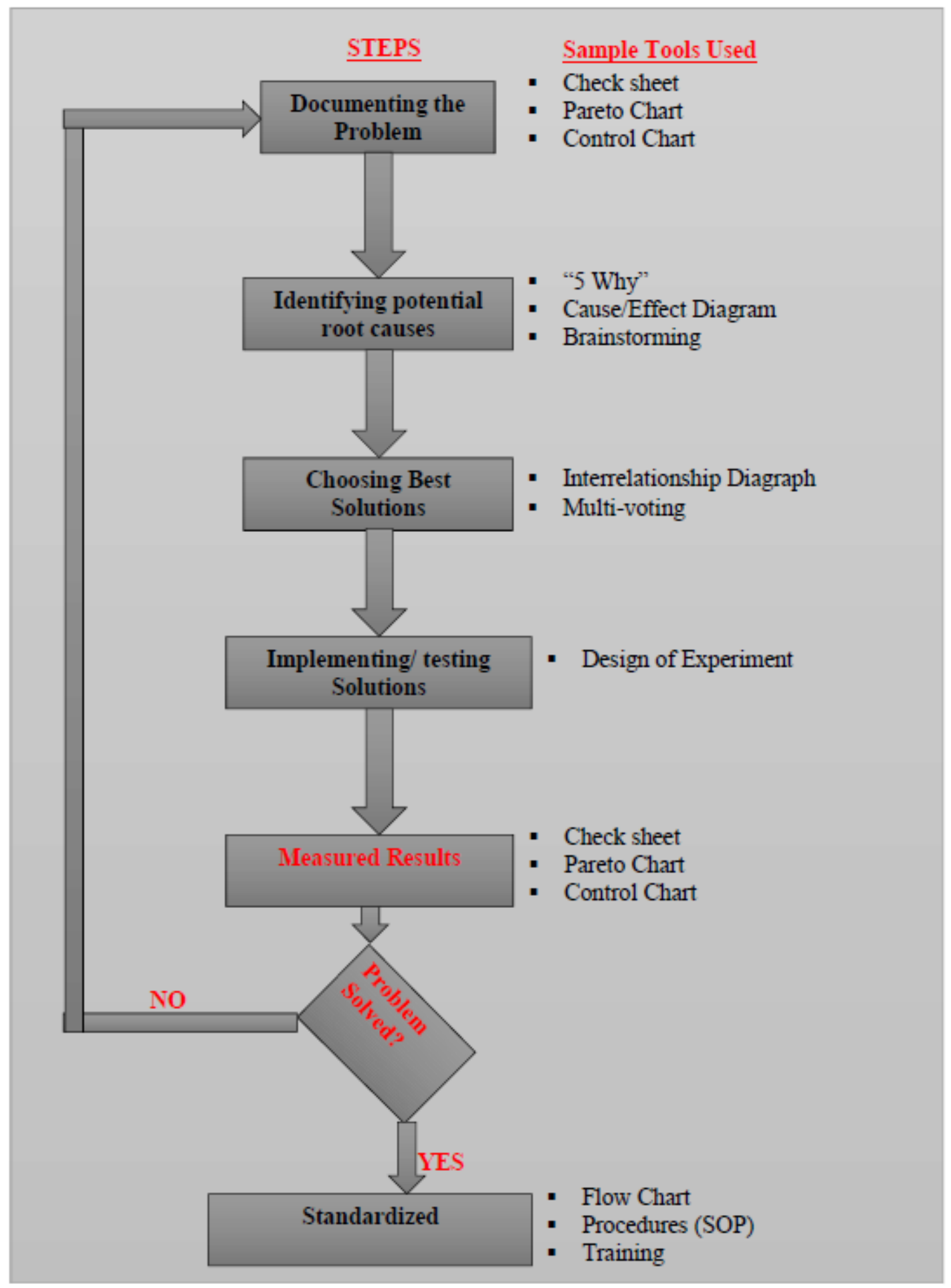

Figure 1. Problem solving flow diagram/strategy

Figure 1. Below summarizes how the problems had been handled as they arose

\section{Key elements of successes in the project}

There were basically three key elements of successes in this project. These are as follows;

Firstly, reporting (both monthly progress reports and final reports) was recognized as a system of interconnect implementation process. Initially in first year, field staffs in their respective groups were interested in completing their individual tasks, without understanding their impact on the overall total 
implementation process. This was later (second year) addressed through creating the system map and flow chart which eventually globalized the world process, with project coordinator overseeing the whole process.

- Secondly, the re-constituted team recognized variations in the implementation process among the groups of field staffs and improved these variations by harmonizing them. There were obvious differences on how the field staffs performed their procedures. As at first there was no standard operating procedures, it enabled these variations.

- Thirdly, the team collected data in the form of cycle time measurements. The data permitted the team to measure the implementation processes. They also allowed the team to assess the situation at the start of the project and quantify the improvement.

- Therefore, statistical thinking philosophy resulted in a substantial reduction of the final reporting time by 60 days. Open defecation reduced from $56.7 \%$ before project implementation to $32.2 \%$ after project implementation in the first year and further to $11.8 \%$ in the second year. The community members (customers) were happy for this reduction.

\section{Definition of variables for objective $i$}

Variables are those factors that define or describe some information. Variables can be Dependent or independent. The dependent variables are those that can be manipulated by the study such as presence of latrines and hand washing facility per household.

Table 1. Variables for sanitation and hygiene per household $(\mathrm{HH})$

\begin{tabular}{|l|l|}
\hline Sanitation variables and sub categories & Hygiene variables \\
\hline Presence of latrines & $\begin{array}{l}\text { Hand washing facility } \\
\text { available and in use }\end{array}$ \\
\hline No latrines & Soap available \\
\hline Acceptable latrines & \\
\hline Latrine with no shelter & \\
\hline Latrine with temporary shelter & \\
\hline & \\
\hline
\end{tabular}

From the list of dependent variables in table 1 above, responses were elicited backed by explanations in column sections as shown in table 2 below;

Table 2. Variables and responses elicited

\begin{tabular}{|l|l|l|}
\hline Items & $\begin{array}{l}\text { Performed in } \\
\text { past 3 months? }\end{array}$ & Comment \\
\hline $\begin{array}{l}\text { (a) Latrine } \\
\text { available }\end{array}$ & $\begin{array}{l}\text { 0. Yes } \\
\text { 1. No }\end{array}$ & \\
\hline $\begin{array}{l}\text { (b) If (a) is Yes, } \\
\text { Latrine } \\
\text { Acceptable? }\end{array}$ & $\begin{array}{l}\text { 0. Yes } \\
\text { 1. No }\end{array}$ & \\
\hline $\begin{array}{l}\text { (c) Hand washing } \\
\text { facility available }\end{array}$ & $\begin{array}{l}\text { 0. Yes } \\
\text { 1. No }\end{array}$ & \\
\hline $\begin{array}{l}\text { (d) If (c) is Yes, } \\
\text { Soap available? }\end{array}$ & $\begin{array}{l}\text { 0. Yes } \\
\text { 1. No }\end{array}$ & \\
\hline
\end{tabular}

\section{Data collection procedures}

The following tools were used; Semi-structured interview guide was prepared in two languages; both English and Kakwa, the local language. Field staffs conducted face-to-face in-depth interviews using the designated guides for each household head. Observation was made for purpose of clarity on the dependent variables. 


\section{Data management, analysis and presentation methods}

Data was cleaned, edited, coded and tallied in computer system, using SPSS. The data was analyzed and presented on tables and also qualitatively described where necessary. Transcriptions of the interviews was analyzed using descriptive thematic analysis for the qualitative components.

\section{Ethical approval and clearance}

The following ethical considerations were taken care of; Ethical clearance and approval from the following offices was sought; office of the District Health Officer (DHO), of Yumbe district local government and office of Senior Assistant Secretary (SAS) for Kerwa Sub County as well as Local Council (LC) III for Kerwa Sub County. Whereas DHO office is an authority in health program at district level, SAS and LC III offices are administrative and political authorities at sub-county level respectively. These three (3) offices all cleared and approved this intervention.

\section{Limitations to the study}

The major limitation to the project was the frequent cross border migration between the two countries (Uganda and South Sudan). This members of certain household, especially household heads, had families in both countries and were less corporative in constructing latrines in both.

\section{Plan for dissemination of results}

The results of the study were disseminated to all the community members in periodic village meetings during and after project implementation. Results were also periodically shared with the relevant offices including office of the District Health Officer (DHO), Senior Assistant Secretary (SAS) for Kerwa Sub county, Local council III and Health Assistant.

\section{Results}

The results are organized as follows;

\section{Results on progressive improvement in sanitation and hygiene in kerwa sub county}

Within the project implementation period, improvements were registered in Sanitation and Hygiene.

Table 3. Results on progressive improvement in sanitation and hygiene in kerwa sub county

\begin{tabular}{|l|l|l|l|}
\hline & Sub county Name: Kerwa Sub County \\
\hline & Before Project & $\begin{array}{l}\mathbf{1}^{\text {st }} \text { Year of Project } \\
\text { Implementation }\end{array}$ & $\begin{array}{l}\mathbf{2}^{\text {nd }} \text { Year of Project } \\
\text { Implementation }\end{array}$ \\
\hline Villages & 43 & 43 & 43 \\
\hline $\begin{array}{l}\text { Total HH with } \\
\text { Latrines }\end{array}$ & 775 & 1215 & 1579 \\
\hline $\begin{array}{l}\text { HH without } \\
\text { toilet }\end{array}$ & 1016 & 576 & 212 \\
\hline $\begin{array}{l}\text { H/H with Hand } \\
\text { Washing } \\
\text { Facility }\end{array}$ & $23(0.85 \%)$ & $17(0.9 \%)$ & $20.8 \%$ \\
\hline $\begin{array}{l}\text { Open } \\
\text { Defecation } \\
\text { percentage }\end{array}$ & $56.7 \%$ & $32.2 \%$ & $11.8 \%$ \\
\hline
\end{tabular}

Table 3 above above shows that total number of households with latrines increased from 775 (43.3\%) in the baseline to $1215(67.8 \%)$ in the first year of project implementation then to $1579(88.2 \%)$ in the second year. Similarly, open defecation dropped from $56.7 \%$ in the baseline to $32.2 \%$ in the first year of project implementation and further to $11.8 \%$ in the second year. Hygiene status, measured using hand washing, almost remained the same between baseline and first year of project implementation at about $0.9 \%$. However, it significantly improved to $20.8 \%$ in the second year. All in all, the rate of improvement in sanitation was more dramatic than the rate of improvement in hygiene status.

When some key community members were asked about the satisfaction with the project outcome, majority of the were quite satisfied. For example; 
"I'm very happy that this improvement has come under my regime. I now know that my people will vote me for second term in office", said Local Council III Chairperson.

\section{Results on quality of latrines in the first year of project implementation}

The quality of latrine was still low in the first year of project implementation despite increase in number of latrines per household. Refer to figure 2 below.

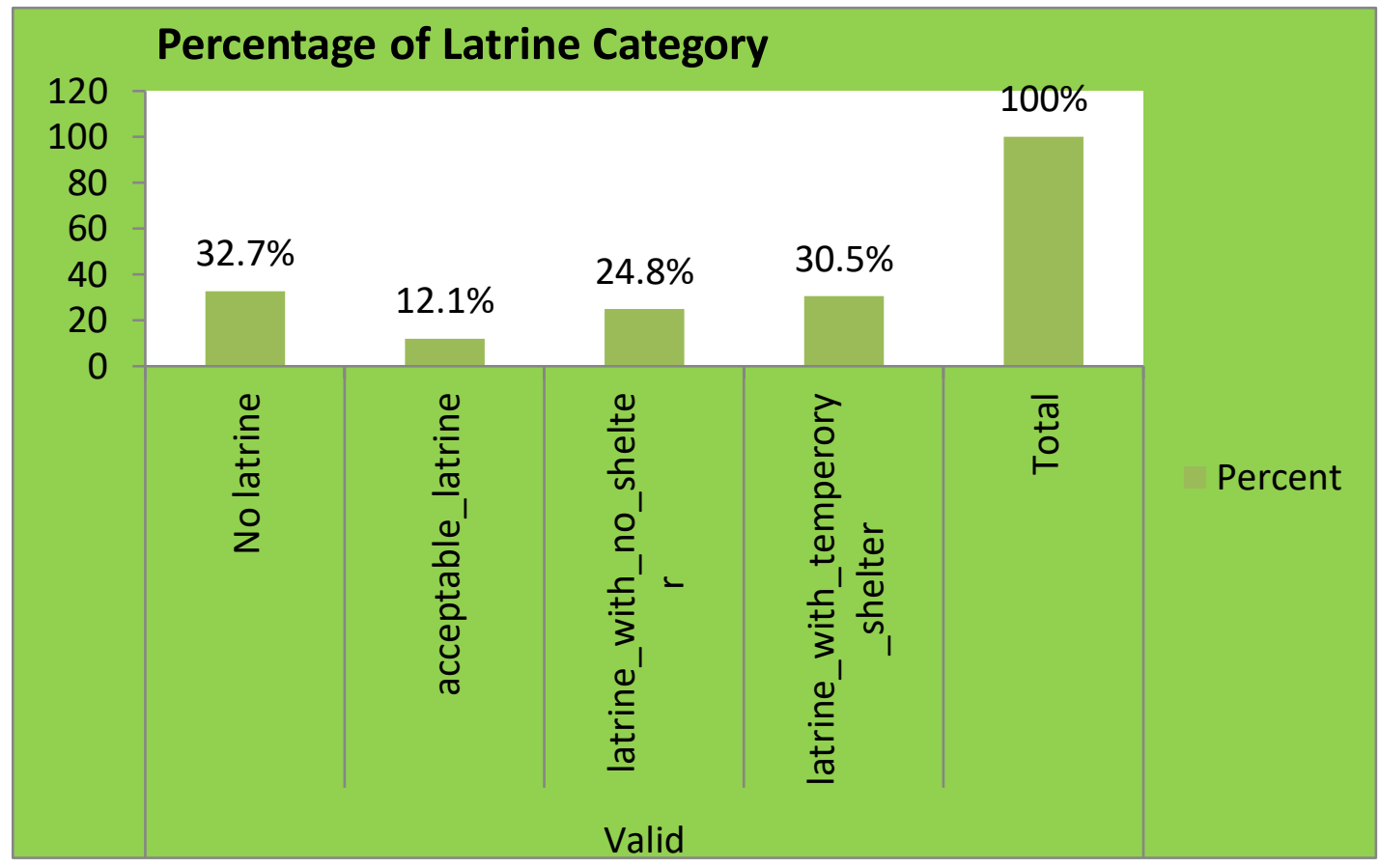

Figure 2. Quality of latrines in the first year of project implementation

Figure 2 above shows that out of the $67.8 \%$ of the households that had latrines, only $12.1 \%$ of the latrines were of the acceptable category after first year of project implementation. The rest of the latrines are either with no shelter or temporary shelter, $24.8 \%$ and $30.5 \%$ respectively. When asked, in one community meeting, on what quality of latrine members desired, one community member reported as follows;

"Why should I spend all my time building expensive latrines. I have two homes; one in South Sudan and another in Uganda, so I'm so busy working for my families to eat."

\section{Discussion, conclusion and recommendation}

\section{Discussion}

In a similar study by Kumar, et al. (2015), it was found that at the beginning of similar community intervention in India, the community was very comfortable with open defecation and toilet construction was a low priority for both men and women. In the same way, for this study, Open defecation reduced from $56.7 \%$ before project implementation to $32.2 \%$ after project implementation in the first year and further to $11.8 \%$ in the second year. The findings are also similar to the work of UNICEF (2016) which argued that one important area of work for sanitation is to end the practice of "open defecation," and facilitate community-led initiatives to build, maintain and use basic toilets. Again, as found by this project that statistical think contributes significantly to project improvement, Doug, et al. (2000) argued in the same way in their conference presentation on improving performance through statistical thinking.

\section{Conclusion}

In conclusion, statistical thinking remains a key process of continuous quality improvement in any industry. If it were not because of intense application of this philosophy, this project would suffer a major drawback. However, as a result of good application, there was a substantial reduction of the final reporting time by 60 days, from 210 days before statistical thinking approach to 150 days after application of the approach. This reduction was even beyond Calvary Chapel management expectation of 180days. Similarly, Open defecation reduced from $56.7 \%$ before project implementation to $32.2 \%$ 
DOI: $10.21522 /$ TIJPH.2013.06.01.Art005

ISSN: $2520-3134$

after project implementation in the first year and further to $11.8 \%$ in the second year. Latrine coverage increased from $43.3 \%$ in the baseline to $67.8 \%$ and $88.2 \%$ in the first and second year of project implementation respectively.

\section{Recommendation}

Based on the success of this project, I would recommend wide-range use of statistical thinking in all healthcare and public health related projects

\section{Acknowledgement}

I do acknowledge all the non-financial and technical capacity contribution made by Calvary Chapel Midigo and SNV Uganda Chapter, which made me access and use the data generated from the Sustainable Sanitation and Hygiene for All Result Project (SSH4A-RP) in Kerwa sub-county.

\section{References}

[1].Amazon. (2017). Improving Performance through Statistical Thinking [Blog Post]. Retrieved from https://www.amazon.com/Improving-Performance-Through-Statistical-Thinking/dp/0873894677

[2].Dig Deep. (2017). what is Sanitation? What is Hygiene? Is there a Difference? [Blog Post]. Retrieved from http://digdeep.org/faqs/what-is-sanitation-what-is-hygiene-is-there-a-difference/

[3].Doug, H., Stu, J., Bob, M., and Tom, P. (2000). Improving Performance through Statistical Thinking. 2000 Minnesota Quality Conference. Retrieved from http://asq.org/statistics/2033/03/improve-performance-usingstatistical-thinking.pdf

[4].Galen, C. B., Donald, W. E., Lynne, B. H., Roger, W. H., Stuart, J. J. \& Janice, E. S. (2010). Improving performance Through Statistical Thinking. Bangalore: New Age International (P) Ltd.

[5].Kumar, S., Rouhani, S., Gautam, A., and Das, M. (2015). "Improving Sanitation and Hygiene Practices of the Rural Poor through Community Institutions in Uttar Pradesh, India". New Delhi: ICRW

[6].Uganda Bureau of Statistic [UBOS]. (2014). National Population and Housing Census 2014. Kampala: Author.

[7].United Nations International Children Emergency Fund [UNICEF]. (2016). Water, Sanitation and Hygiene (WASH) [Blog Post]. Retrieved from https://www.unicef.org/wash/3942_3952.html

[8].World Health Organization [WHO]. (2017). Sanitation [Blog Post]. Retrieved from http://www.who.int/topics/sanitation/en/ World Health Organization [WHO]. (2011). Water, Sanitation and Hygiene _ Diarrhoea [Blog Post]. Retrieved from http://www.who.int/elena/titles/bbc/wsh_diarrhoea/en/ 